\title{
Effect of female only versus coed physical education classes on social physique anxiety in $7^{\text {th }}$ grade girls
}

\author{
Prewitt, Steve $^{1,}$, , James Hannon ${ }^{1}$, Timothy Brusseau ${ }^{1}$, Maria Newton ${ }^{1}$, Janet Shaw ${ }^{1}$, \\ Julia Summerhays ${ }^{2}$ \\ ${ }^{1}$ Department of Exercise and Sport Science, University of Utah, Salt Lake City, USA \\ ${ }^{2}$ Department of Health Promotion and Education, University of Utah, Salt Lake City, USA
}

Email address:

steve.prewitt@utah.edu(Prewitt, S.)

\section{To cite this article:}

Prewitt, Steve, James Hannon, Timothy Brusseau, Maria Newton, Janet Shaw, Julia Summerhays. Effect of Female Only Versus Coed Physical Education Classes on Social Physique Anxiety in 7th Grade girls. International Journal of Secondary Education.

Vol. 1, No. 5, 2013, pp. 26-30. doi: 10.11648/j.ijsedu.20130105.13

\begin{abstract}
It is well documented that there is a significant decrease in the enjoyment and participation of adolescent females in physical education (PE) classes. Adolescent females report a desire for single sex classes due to increased feelings of social physique anxiety (SPA). Therefore, the purpose of this pilot study was to examine changes in SPA of $7^{\text {th }}$ grade females in same sex and coed PE classes. Forty-two $7^{\text {th }}$ grade females from a junior high school in the Mountain West region of the United States participated in this pilot study. Group one participated in a female-only class, while group two remained in the school's traditional coed class format. Scores from the Social Physique Anxiety Scale were used to measure change during a three week unit. A 2 x 2 ANCOVA was conducted to examine changes in SPA scores. Results revealed no significant changes between groups or within groups. However, a trend was observed with the same sex group's SPA scores decreasing $(9.75 \%)$ and coed scores increasing (8.3\%). Several articles have examined same sex versus coed PE classes, but few have examined SPA within a middle school physical education setting. This study provides a starting point to further examine adolescent SPA in PE.
\end{abstract}

Keywords: Single Gender, Physical Education, Social Physique Anxiety

\section{Introduction}

Physical education classes provide the best opportunity for increasing physical activity (PA) $[1,2]$ and helping all students to develop a positive attitude towards PA [3]. This is generally accomplished during the elementary school years, but PA and attitudes gradually decline throughout the secondary school years [4]. Trudeau and Shepard [3] suggested that this decrease is not attributable to a reduction in the interest of physical education in general, but more likely influenced by the format and content of the class. As students age and undergo physical maturity, physique-related perceptions can lead to a potential decrease in the desire to be physically active. Physical education classes are traditionally coed, and significant differences in maturation, virtually nonexistent during elementary school years, along with subsequent alterations of fitness levels [5, 6], can be a leading cause of not wanting to participate. Jackson et al. [7] reported an inverse relationship between maturation status and PA in adolescent females, suggesting that as maturation increases, PA levels decrease.

Decreases in PA among females might also be associated with Social Physique Anxiety (SPA), a response to elevated self-presentation concerns in the context. Specifically, SPA is the anxiety an individual feels due to the perception that their body or physique is being evaluated or judged by others [8]. Individuals with little or no self-presentation concerns may respond with feelings of motivation and a desire to improve their physique or fitness levels. On the other hand, individuals with elevated self-presentation concerns and the accompanying SPA may hide, deflect, or abstain from activities that draw attention to the body. This apprehension or nervousness regarding their physical appearance can start at a young age and is usually accentuated by environments where a person's body is on display, such as a swimming pool, fitness center, or physical education class $[9,10]$. This situational response can be more pronounced during periods of physical maturation [11].

Early adolescence can be a pivotal time in the development of attitudes towards PA. Several authors have 
explored the relationship that higher SPA can have on attitudes towards PA and physical education [9, 12, 13]. In general findings from this research suggest an inverse relationship between SPA and positive attitudes surrounding PA and physical education. For example, Brunet and Sabiston [14] reported significant negative correlations between SPA and the three tenets of Basic Needs Theory, suggesting that increases in SPA can have a significant influence on individuals' motivation towards PA. Regular engagement in PA is extremely important for the proper growth and development of adolescents. A growing concern amongst policy makers and those involved in PA research and promotion is the significant decrease in activity levels of adolescents, particularly females [15]. One key to helping teenagers lead a healthier life is helping them increase their PA levels. Therefore, research needs to examine ways to help girls become more active during their adolescent years.

The decline of PA levels in adolescent females has occurred despite the passage of Title IX in 1972, which opened up additional opportunities for females in sport and physical education. One of the greatest changes of this law was the creation of coed physical education classes rather than the traditional same sex environments. Title IX did increase the equality within physical education by providing equal access to facilities and equipment [16]. Recently however, a debate has ensued as to whether coed or same sex physical education classes provide the best learning environment. Several authors have observed significant increases in PA by female students in coed classes compared to those in same sex classes $[17,18]$. Other studies have suggested that the coed environment prevents female students from fully engaging and that they themselves desire same sex classes [19]. A viable concern voiced by females is "performance" in front of the opposite sex. Osborne, Bauer, and Sutliff [20] commented that a major issue with coed classes, expressed by the students, was the feelings of discomfort when performing certain activities (e.g., stretching) around the opposite sex. Olafson [21] reports similar comments from female students. They referred to discomfort during physical education classes with males with comments including feeling self-conscious that others are staring at their bodies and anxiety pertaining to performance in front of boys. Finally, the participants expressed a tremendous desire for an all-girls class stating that it would alleviate many barriers to participation in physical education. Yin and Ryska [22] also examined differences in SPA and task enjoyment between a single sex female only physical education class and a coed class during practice and testing sessions. They reported no differences between groups for SPA, but those in the female only group reported greater task enjoyment than those in the coed group.

Given the current debate over which learning environment is more beneficial to female students, more research is needed exploring various outcomes within coed and single sex environments. Therefore, the purpose of this pilot study was to examine the effect of sex environment on
SPA in $7^{\text {th }}$ grade females during a resistance training unit. It was hypothesized that the participants in the female only group would report a greater decrease in SPA levels than their coed counterparts. This pilot study is significant because it adds to the body of research examining the effect of sex environment on SPA.

\section{Methodology}

\subsection{Participants}

A convenience sample of 42 female $7^{\text {th }}$ graders (mean age $=12.4$ years \pm 0.5 ) in two physical education classes was recruited from a junior high school in the Mountain West region of the United States. University Institutional Review Board and school district approval was obtained as well as parental consent and participant assent. Traditionally, physical education classes were taught in a coed manner at the school. Participants were assigned to two groups based upon their current physical education class period to keep classes intact, with one class randomly assigned as the same sex group. Group $1(\mathrm{n}=20)$ consisted of students in a female only class, while Group 2 (female $=22$ ) remained in a traditional coed physical education class. Descriptive statistics can be observed in Table 1. The school's two physical education teachers, one male (10 years of experience) and one female (17 years of experience) monitored the activities, with both teachers co-teaching the coed class and the female teacher supervising the same sex group.

Table 1. Means \pm Standard Deviations for Physical Characteristics for 7th Grade Females

\begin{tabular}{lll}
\hline & $\begin{array}{l}\text { Coed Group } \\
(\mathbf{n = 2 4 )}\end{array}$ & $\begin{array}{l}\text { Female Only } \\
\text { Single Sex }(\mathbf{n}=\mathbf{2 0})\end{array}$ \\
\hline Age (years) & $12.41 \pm 0.50$ & $12.40 \pm 0.50$ \\
Height (inches) & $61.96 \pm 2.96$ & $62.0 \pm 2.67$ \\
Weight (pounds) & $113.63 \pm 33.55$ & $111.45 \pm 16.66$ \\
Body Mass Index & $20.74 \pm 5.86$ & $19.78 \pm 2.56$ \\
\hline
\end{tabular}

\subsection{Instrumentation}

The Social Physique Anxiety Scale (SPAS) [23] is a measurement tool used to analyze an individual's perception of self-presentation or how they believe their physical appearance appears to others. Smith [25] recommended the use of the 9-item SPAS (Figure 1) when measuring adolescent populations compared to Hart's original 12 item scale. The SPAS uses a five-point Likert-type scale $(1=$ not at all, 5 = extremely) with the lowest score (9) signifying low anxiety and the highest (45) signifying extreme social physique anxiety. Scoring of the SPAS is standard summation of answers with questions five and eight being reversed scored. Sample questions include, "I wish I wasn't so up-tight about my physique or figure," and "When in workout clothes, I often feel nervous about how well-proportioned my body is." 


\subsection{Procedures}

On the Friday prior to the start of the intervention, participants completed the SPAS inventory to establish a baseline. This was completed during the regular physical education class. Participants were read the introduction as it appears on the SPAS. The only modification was the addition of "in this PE class." The following week, students in Group 1 were instructed of the changes occurring during the intervention. For the next three weeks (6 class periods), students participated in a resistance training unit consisting of exercises geared towards general fitness (Table 2) per recommendations from the American Academy of Pediatrics [25]. Exercises were completed in a circuit format using a variety of modalities including dumbbells, resistance bands, body weight, and stability/yoga balls. Due to scheduling employed by the school and size of class, each group participated in two circuit training sessions per week along with two days of basketball activity. Groups 1 and 2 maintained their single sex and coed group membership throughout the study in both circuit training and basketball. Each session began in the main gym in a coed environment for the purpose of roll and warm-ups to accommodate multiple classes using the same gym space. Each circuit training session consisted of 32 minutes of resistance training, ending with 3-5 minutes of cool down and stretching. Participants were engaged in 8 stations per rotation, with each station lasting 45 seconds followed by 15 seconds of rest/transition time to the next station. Participants were able to accomplish four rotations a day during the allotted class time. Stations rotated each day with like exercises (upper body, lower body, etc.) exchanged for variety. During off days when students were not engaged in circuit training, they participated in basketball. Upon completion of the intervention, students completed the SPAS inventory to determine potential changes.

Table 2. List of Exercises Performed

\begin{tabular}{llll}
\hline Upper Body & Lower Body & Abs/Core & Cardio/Other \\
\hline Arm Curls & Wall Sits & Sit ups & Jump Rope \\
Climbing Wall & Lunges & Planks & Jumping Jacks \\
Lat Pull downs & Body Squats & Medicine Ball & Shuttle Run \\
Pull-ups & Leg lifts & throws & Agility Ladder \\
"Skull Crushers" & Ski Jumps & Scissor Kicks & Double Ladder \\
Push ups & Step Ups & & Jog in Place \\
Triceps lifts & Long Jumps & & \\
\hline
\end{tabular}

\section{Results}

This study used a quasi-experimental non-equivalent group design [26]. Data were analyzed using SPSS 20.0 (SPSS, Inc., Chicago, IL). Data were checked for missing values, outliers, and normality. Missing data were excluded pairwise during the analysis. Statistical significance was set at the 0.05 level for all analyses. Internal consistency was evaluated for each testing measure. Data were initially analyzed using one-way analysis of variance (ANOVA) to determine group differences in pretest SPA scores as was testing for normality and homogeneity of variance. Findings indicated that the coed group reported significantly lower values for SPA $(M=21.86 \pm S D=8.74)$ compared to the single sex female only group $(\mathrm{M}=27.00 \pm \mathrm{SD}=6.62)[\mathrm{F}(1$, 42) $=6.582, p=0.014]$.

Campbell and Stanley [26] commented that significant differences can be observed during pretesting when using intact groups (such as the case when working in a school setting) where randomization does not, or cannot take place. Thus, an ANCOVA was conducted examining post-test results based upon group membership using participants' pretest SPA scores as the covariate. This analysis revealed no statistically significant difference in SPA scores between the single sex female only group $(\mathrm{M}=25 \pm \mathrm{SD}=6.48)$ and the coed group $(\mathrm{M}=23.23 \pm \mathrm{SD}=10.11)[\mathrm{F}(1,41)=2.899$, $\mathrm{p}=0.097$ ] at post-test. Although a significant difference was not reported, an interesting trend was observed: participants in the coed group had an $8.3 \%$ increase in SPA values demonstrating an increase in anxiety while the single sex female only group reported a decrease of $9.75 \%$, signifying lower anxiety levels (Fig. 1).

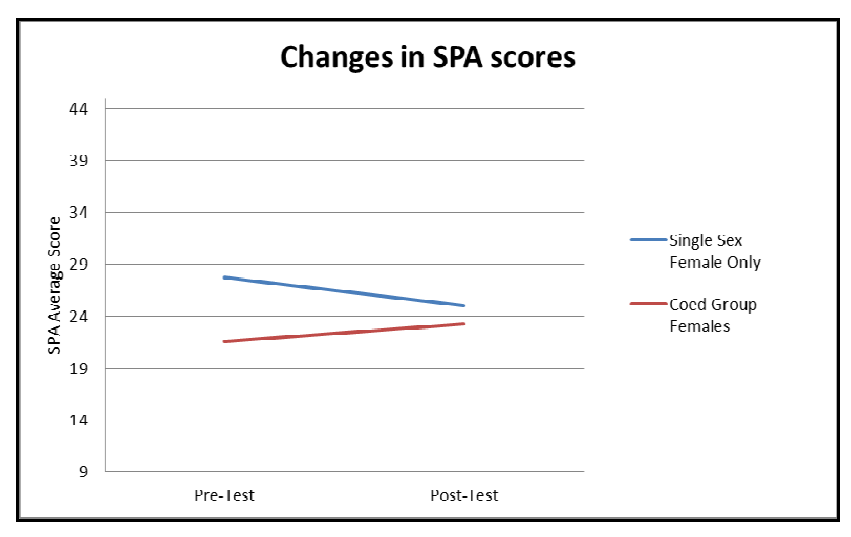

Figure 1. Changes in SPA scores

\section{Discussion}

This pilot study sought to examine the effect participating in a female only single sex class compared to a traditional coed class had on SPA in middle school girls. SPA outcomes were not statistically significant; however, an interesting trend was noted. Participants in the coed group began this study with a lower group mean SPA score than the same sex group and increased their SPA scores $8.3 \%$, whereas the female only single sex group reported a decrease of $9.75 \%$. These results correspond to the literature suggesting that female SPA increases in the presence of the opposite sex and decreases in same sex environments [19]. The results also support previous qualitative studies in which girls have indicated feeling uncomfortable with their bodies on display amongst boys in coeducational settings [20,21]. While these results do not support the original hypothesis, the trend lends to the original concept that SPA decreases in same sex environments. It is important to note that this study was conducted over one unit in a semester long class. Further studies need to include a longer time frame over more units. 
This idea is supported by Scott et al. [27] who reported no changes in SPA during the first three weeks of their intervention with college students, but did observe significant decreases from baseline to week 6. Similar changes in self-esteem have been reported following longer intervene-tions ( $\sim 12$ weeks) [28]. Care should be taken when interpreting these results as outcomes may have been different if a different instructional model was implemented (i.e., peer teaching, cooperative teaching) or if the curriculum included information regarding values, social skills, or discussions around body image.

There were at least a couple of limitations to this study. During this study, three weeks were used for the intervention as that is the usual length of time of time allotted per instructional unit at the school. As such, participants only engaged in six sessions. This may not have allowed enough time for significant changes in thoughts regarding self-presentation. In a previously mentioned study, Scott and others [27] did not report changes in SPA until after six weeks of their intervention.

A second probable limitation is the sample size of the study. An a priori power analysis suggested a sample size of 42 participants was needed for a medium effect size (Cohen's $d=0.5$ ). Results showed a partial í2 of 0.071 , demonstrating an effect size of 0.26 , and an observed power of 0.382 . With the sample size at the minimal, potential significance might not have been observed due to decreases in effect size and power. Therefore this study was underpowered.

A third limitation may have been pre-existing views of physical education in general. Previous research suggests that there is a significant decrease in the activity level of adolescent students [4, 29]. Therefore students' perceptions of physical education may override feelings of SPA.

\section{Conclusion}

This pilot study sought to add to the literature regarding PA and SPA in $7^{\text {th }}$ grade females. The majority of research on SPA has been on older individuals and has not addressed this younger demographic. We were able to examine changes in SPA within coed and single sex female only PE environments. The practical implications for physical education teachers based on the results of this study are mixed. The results indicated potential decreases in SPA following a same sex resistance training class. While Title IX does sanction the implementation of coed classes for physical education, stipulations within the law allow for same sex environments, including potential physical injury (contact sports) and other activities deemed harmful in the best interests of the students. The question that arises is how important is SPA to the long term participation of adolescent females in PA. It is the authors' opinion that decreases in SPA will prove more favorable to increasing participation in physical education and therefore increasing PA. However, these recommendations must be taken with caution as this is based on a single study. Although no significant differences were observed, this study serves as a starting point for future research into the possible psychosocial advantages of same sex physical education. More research needs to be done to examine other variables that may influence feelings of SPA including type of activity, incorporation of knowledge [27], and multiple ages.

\section{References}

[1] R. R. Pate, D. S. Ward, J. R. O'Neill, and M. Dowda, "Enrollment in physical education is associated with overall physical activity in adolescent girls," Research Quarterly for Exercise and Sport, vol. 78, no. 4, pp. 265-270, 2007.

[2] J. F. Sallis, T.L. McKenzie, M. W. Beets, A. Beighle, H. Erwin, and S. Lee, "Physical education's role in public health: steps forward and backward over 20 years and HOPE for the Future," Research Quarterly for Exercise and Sport, vol. 83, no. 2, pp. 125-135, 2012.

[3] F. Trudeau and R. J. Shephard, "Contribution of school programmes to physical activity levels and attitudes in children and adults," Sports Medicine, vol. 35, no. 2, pp. 89-105, 2005.

[4] W. Van Mechelen, J.W.R. Twisk, G.B. Post, J. Snel, and H.C.G. Kemper, "Physical activity of young people: The Amsterdam longitudinal growth and health study," Medicine and Science in Sports and Exercise, vol. 32, pp. 1610-1616, 2000 .

[5] S. P. Cumming, M. Standage, F. B. Gillison, T. P. Dompier, and R. M. Malina, "Biological maturity status, body size, and exercise behaviour in British youth: A pilot study," Journal of Sports Sciences, vol. 7, pp. 677-686, 2009.

[6] R. M. Malina, "Physical growth and biological maturation of young athletes," Exercise and Sport Sciences Reviews, vol. 22, pp. 389-433, 1994.

[7] L. Jackson, S. P. Cumming, C. Drenowatz, M. Standage, L. B Sherar, L. B. and R. M. Malina, "Biological maturation and physical activity in adolescent British females: The roles of physical self-concept and perceived parental support," Psychology of Sport and Exercise, vol. 14, pp. 447-454, 2013.

[8] E. A. Hart, M. R. Leary, and W. J. Rejeski, "The social physique anxiety," The Journal of Sport \& Exercise Psychology, vol. 11, pp. 94-104, 1989.

[9] S. Whitehead and S. Biddle, "Adolescent girls' perceptions of physical activity: a focus group study," European Physical Education Review, vol. 14, no. 2, pp. 243-262, 2008.

[10] C. Cockburn and G. Clarke, "'Everybody's looking at you!': Girls negotiating the 'femininity deficit' they incur in physical education," Women's Studies International Forum, vol. 25 , no. 6 , pp. 651-665, 2002.

[11] A. Niven, S. Fawkner, A. Knowles, J. Henretty, and C. Stephenson, "Social physique anxiety and physical activity in early adolescent girls: the influence of maturation and physical activity motives" Journal of Sports Sciences, vol. 27, no. 3, pp. 299-305, 2009.

[12] M. S. Hagger and A. Stevenson, "Social physique anxiety and physical self-esteem: Gender and age effects," 
Psychology and Health, vol. 25, no. 1, pp. 89-110, 2010.

[13] M. Lindwall and E. Lindgren, "The effects of a 6-month exercise intervention programme on physical self-perception and social physique anxiety in non-physically active adolescent Swedish girls," Psychology of Sport and Exercise, vol. 6, pp. 643-658, 2005.

[14] J. Brunet and C. M. Sabiston, "Social physique anxiety and physical activity: A self-determination theory perspective," Psychology of Sport and Exercise, vol. 10, no. 3, pp. 1-7, 2009.

[15] US Department of Health and Human Services. Retrieved from http://www.hhs.gov.

[16] J. C. Hannon and S. M. Williams, "Should secondary physical education be coeducational or single-sex?," Journal of Physical Education, Recreation \& Dance, vol. 79, no. 2 , pp. 6-56, 2008.

[17] T. L. McKenzie, J. J. Prochaska, J. R. Sallis, and K. J. LaMaster, "Coeducational and single sex physical education in middle schools: Impact on physical activity," Research Quarterly for Exercise and Sport, vol. 75, pp. 446-449, 2004.

[18] R. van Acker, F. Carreiro da Costa, I. De Bourdeaudhuij, G. Cardon, and L. Haerens, "Sex equity and physical activity levels in coeducational physical education: exploring the potential of modified game forms," Physical Education and Sport Pedagogy, vol. 15, no. 2, pp. 159-173, 2010.

[19] L. D. Kruisselbrink, A. M. Dodge, S. L. Swanburg, and A. L. MacLeod, "Influence of same-sex and mixed-sex exercise settings on the social physique anxiety and exercise intentions of males and females," Journal of Sport \& Exercise Psychology, vol. 26, pp. 616-622, 2004.

[20] K. Osborne, A. Bauer, and M. Sutliff, "Middle school students' perceptions of coed versus non-coed physical education," Physical Educator, vol. 59, no. 2, pp. 83-89, 2002.
[21] L. Olafson, "'I hate phys. ed.': Adolescent girls talk about physical education," Physical Educator, vol. 59, no. 2, pp. 67-74, 2002.

[22] Z. Yin and T. A. Ryska, "Perceived competence, social anxiety about physique, and enjoyment in testing situations among groups of mixed sex and girls only," Psychological Reports, vol. 84, no. 2, pp. 381-385, 1999.

[23] K. A. Martin, W. J. Rejeski, M. R. Leary, E. McAuley, and S. Bane, "Is the social physique anxiety scale really multidimensional? Conceptual and statistical arguments for a unidimensional model," Journal of Sport \& Exercise Psychology, vol. 19, pp. 359-367, 1997.

[24] L. Smith, "Measurement of social physique anxiety in early adolescence," Medicine and Science in Sports and Exercise, vol. 36, no. 3, pp. 475-483, 2004.

[25] American Academy of Pediatrics, "Strength training for children," Pediatrics, vol. 121, no. 4, pp. 835-840, 2008.

[26] D. T. Campbell and J. C. Stanley, Experimental and quasi-experimental designs for research on teaching, American Educational Research Association, Boston, MA, 1963.

[27] L. A. Scott, A. B. Joner, D. R., Czech, B. A. Munkasy, and S. Todd, "Effects of exercise and a brief education intervention on social physique anxiety in college students," International Journal of Fitness, vol. 5, no. 1, pp. 9-17, 2009.

[28] R. D. DeBate, K. P. Gabriel, M. Zwald, J. Huberty, and Y. Zhang, "Changes in psychosocial factors and physical activity frequency among their- to eighth-graders who participated in a developmentally focused youth sport program: A preliminary study," Journal of School Health, vol. 79, pp. 474-484, 2009.

[29] M. Song, D.D. Carroll, and J.E. Fulton. "Meeting the 2008 physical activity guidelines for Americans among U.S. youth," American Journal of Preventative Medicine, vol. 44, pp. 216-222, 2013. 